JPE 11-6-6

\title{
Fuzzy PD Speed Controller for Permanent Magnet Synchronous Motors
}

\author{
Jin-Woo Jung*, Han Ho Choi*, and Tae-Heoung Kim ${ }^{\dagger}$ \\ * Division of Electronics and Electrical Engineering, Dongguk University, Seoul, Korea \\ $\dagger$ Dept. of Electrical Engineering, Engineering Research Institute, Gyeongsang National University, Jinju, Korea
}

\begin{abstract}
This paper presents a fuzzy PD speed control scheme for the robust speed tracking of a permanent magnet synchronous motor (PMSM). Motivated by the common control engineering knowledge that transient performance can be improved if the $\mathrm{P}$ gain is big and the D gain is small in the beginning, a linearizing control scheme with a fuzzy PD controller is proposed. The global system stability is analyzed and the proposed control algorithm is implemented using a TMS320F28335 DSP. Simulation and experimental results are given to verify the effectiveness of the proposed method.
\end{abstract}

Key Words: Fuzzy control, PD control, Permanent magnet synchronous motor (PMSM), Robust control, Speed control

\section{INTRODUCTION}

Permanent magnet synchronous motors (PMSM) are extensively used in high-performance drives such as servo and traction applications owing to the advantages of a high power density, a high efficiency, low inertia, and low noise [1]-[8]. However, PM synchronous motors are not easily controlled due to their nonlinear characteristics and uncertainties such as system parameter variations, unmodeled dynamics and external load disturbances. To solve these problems several researchers such as [4]-[8] have recently proposed fuzzy control design methods for a permanent magnet synchronous motors. Fuzzy control theory provides an alternative tool for collecting human knowledge and for dealing with nonlinearities or uncertainties, and it has succeeded in controlling complex nonlinear or uncertain systems that are not amenable to conventional control methods [9], [10]. The PMSM fuzzy control design methods presented in [4]-[8], and the references therein are based on the heuristics-based fuzzy approach which is essentially model free. However, as pointed out in [9] these methods can have two major drawbacks. They do not have a systematic and tractable design technique, and thus analysis of stability, performance or robustness of the control system is very difficult.

Taking these facts into account a nonlinear control scheme for the robust speed control of a PM synchronous motor is proposed. The proposed speed control law consists of two controllers: a linearizing controller and a fuzzy PD

Manuscript received Apr. 1, 2010; revised May 6, 2011

Recommended for publication by Associate Editor Jang-Mok Kim.

$†$ Corresponding Author: ktheoung@gnu.ac.kr

Tel: +82-55-772-1717, Gyeongsang National University

* Division of Electronics and Electrical Engineering, Dongguk University, Korea controller. The linearizing controller linearizes the nonlinear PMSM model, while the fuzzy PD controller stabilizes the linearized dynamics. The PD parameters are chosen based on the common control engineering knowledge that transient performance can be improved if the $P$ gain is big and the $D$ gain is small in the beginning [10]. Unlike the previous fuzzy control design methods of [4]-[8], the global stability of the proposed control system can be guaranteed. By using the results from [11], the asymptotic stability is proven. Simulation and experimental results are given to confirm the feasibility of the proposed control method.

\section{PMSM MODEL DESCRIPTION}

In the rotor flux oriented synchronous rotating reference frame, a surface-mounted permanent magnet synchronous motor (PMSM) can be represented by the following equation:

$$
\begin{aligned}
& \dot{\omega}=k_{1} i_{q s}-k_{2} \omega-k_{3} T_{L} \\
& \dot{i}_{q s}=-k_{4} i_{q s}-k_{5} \omega+k_{6} V_{q s}-\omega i_{d s} \\
& \dot{i}_{d s}=-k_{4} i_{d s}+k_{6} V_{d s}+\omega i_{q s}
\end{aligned}
$$

where, $T_{L}$ represents the load torque, $\omega$ is the electrical rotor angular speed, $i_{q s}$ is the q-axis current, $V_{q s}$ is the q-axis voltage, $i_{d s}$ is the d-axis current, $V_{d s}$ is the d-axis voltage, and $k_{i}>0, i=1, \cdots, 6$ are the parameter values depending on the stator resistance $R_{s}$, the stator inductance $L_{s}$, the number of poles $p$, the equivalent rotor inertia $J$, the viscous friction coefficient $B$, and the magnetic flux $\lambda_{m}$.

$$
\begin{aligned}
& k_{1}=\frac{3}{2} \frac{1}{J} \frac{p^{2}}{4} \lambda_{m}, k_{2}=\frac{B}{J}, k_{3}=\frac{p}{2 J}, \\
& k_{4}=\frac{R_{s}}{L_{s}}, k_{5}=\frac{\lambda_{m}}{L_{s}}, k_{6}=\frac{1}{L_{s}}
\end{aligned}
$$

In this paper, the following assumptions are used to design the fuzzy PD speed controller: 
A1: $\theta, \omega, i_{q s}$, and $i_{d s}$ are available.

A2: $\dot{T}_{L}$ can be neglected and it can be set to $\dot{T}_{L}=0$.

A3: The desired speed $\omega_{d}$ is twice differentiable and $\omega_{d}$, $\dot{\omega}_{d}$, and $\ddot{\omega}_{d}$ are bounded.

It should be noticed that almost all of the previous control law design methods were based on the above assumptions.

\section{FuZzy PD Speed Controller Design AND STABILITY ANALYSIS}

\section{A. Linearized Error Dynamics}

The control inputs $V_{q s}$ and $V_{d s}$ can be decomposed as:

$$
\begin{aligned}
V_{q s} & =\frac{1}{k_{1} \cdot k_{6}}\left(u_{f b q}+u_{f q}\right) \\
V_{d s} & =\frac{1}{k_{6}}\left(u_{f b d}+u_{f d}\right)
\end{aligned}
$$

Based on the feedback linearization method given in [12] and [13], the linearizing control terms $u_{f q}$ and $u_{f d}$ can be computed by:

$$
\begin{aligned}
& u_{f q}=\ddot{\omega}_{d}+k_{2} \alpha+k_{1} k_{4} i_{q s}+k_{1} k_{5} \omega+k_{1} \omega i_{d s} \\
& u_{f d}=k_{4} i_{d s}-\omega i_{q s}
\end{aligned}
$$

where, $\alpha=k_{1} i_{q s}-k_{2} \omega-k_{3} T_{L}=\dot{\omega}$. The linearizing control law results in the following linear time-invariant error dynamics:

$$
\dot{\omega}_{e}=\alpha_{e}, \dot{\alpha}_{e}=u_{f b q}, \dot{i}_{d s}=u_{f b d}
$$

where, $\omega_{e}=\omega-\omega_{d}$ and $\alpha_{e}=\dot{\omega}_{e}=\alpha-\dot{\omega}_{d}$. If $u_{f b q}$ and $u_{f b d}$ are set to:

$$
u_{f b q}=-K_{P} \omega_{e}-K_{D} \frac{d}{d t} \omega_{e}, u_{f b d}=-K_{3} i_{d s}
$$

Then the closed-loop control system is given by:

$$
\dot{e}=\left[\begin{array}{ccc}
0 & 1 & 0 \\
-K_{P} & -K_{D} & 0 \\
0 & 0 & -K_{3}
\end{array}\right] e
$$

where, $\mathrm{e}=\left[\omega_{e}, \alpha_{e}, i_{d s}\right]^{T}$, and the characteristic function of the closed-loop control system is given by the following thirdorder polynomial:

$$
s^{3}+a_{2} s^{2}+a_{1} s+a_{0}
$$

where, $a_{2}=K_{D}+K_{3}, a_{1}=K_{3} K_{D}+K_{P}$, and $a_{0}=K_{3} K_{P}$. In many previous papers such as [6], [14], [15], the dynamic characteristics of $i_{d s}$ are neglected to simplify the stability analysis under the assumption that the $d$-axis current controller works well and that the output $i_{d s}$ satisfies $i_{d s}=0$. However, in this paper, the dynamics of $i_{d s}$ are considered for a rigorous stability analysis, as well as the PD control term $u_{f b q}$ and the linearizing control term $u_{f q}$.

\section{B. Fuzzy PD Speed Controller}

The common rule given in [10] implies that the transient performance can be improved if the $P$ gain is big and the $D$ gain is small when the error is big. Considering this rule the conventional PD controller (4) was modified. The proposed fuzzy PD control input $u_{f b}$ is determined by five fuzzy rules of the following form:

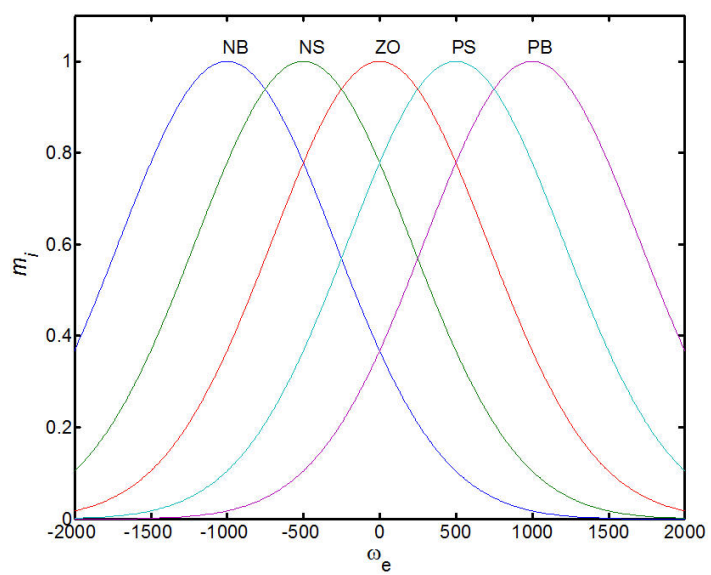

Fig. 1. Membership functions.

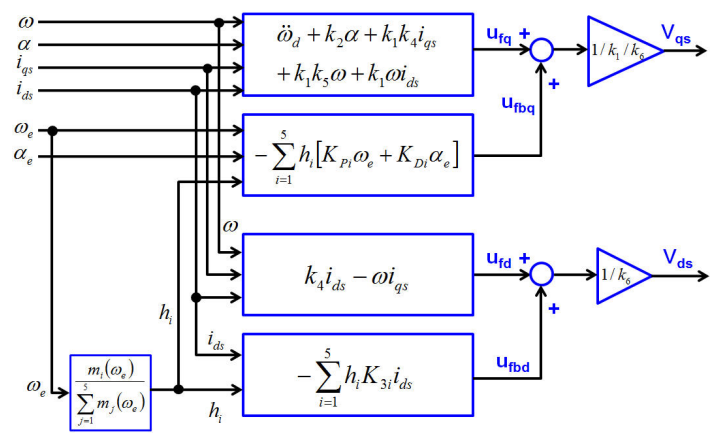

Fig. 2. Block diagram of the proposed fuzzy PD speed controller.

Rule $i$ : IF $\omega_{e}$ is $F_{i}$, THEN $u_{f b q}=-K_{P i} \omega_{e}-K_{D i} \alpha_{e}, u_{f b d}=$ $-K_{3 i} i_{d s}$

where, $F_{i}(i=1, \ldots, 5)$ are the fuzzy sets, $K_{P 1} \geq K_{P 2} \geq K_{P 3}$ $>0, K_{D 3} \geq K_{D 2} \geq K_{D 1}>0, K_{31} \geq K_{32} \geq K_{33}>0, K_{P 5} \geq$ $K_{P 4} \geq K_{P 3}>0, K_{D 3} \geq K_{D 4} \geq K_{D 5}>0$, and $K_{35} \geq K_{34} \geq$ $K_{33}>0$. The membership functions $m_{i}$ according to the speed error $\omega_{e}$ is shown in Fig. 1 . In this figure, $\mathrm{ZO}\left(F_{3}\right)$ stands for zero, PS $\left(F_{4}\right)$ for positive small, PB $\left(F_{5}\right)$ for positive big, NS $\left(F_{2}\right)$ for negative small, and NB $\left(F_{1}\right)$ for negative big.

By using a standard fuzzy inference method (using a singleton fuzzifier, a product fuzzy inference and a weighted average defuzzifier), the final fuzzy PD control input is obtained as:

$$
\begin{aligned}
& u_{f b q}=-\sum_{i=1}^{5} h_{i}\left[K_{P i} \omega_{e}+K_{D i} \frac{d}{d t} \omega_{e}\right], \\
& u_{f b d}=-\sum_{i=1}^{5} h_{i} K_{3 i} i_{d s}
\end{aligned}
$$

where, $h_{i}=m_{i} / \sum_{j=1}^{5} m_{j}$ is the normalized weight of each IFTHEN rule and it satisfies $h_{i} \geq 0$ and $\Sigma h_{i}=1$. Fig. 2 shows a block diagram of the proposed fuzzy PD speed controller.

\section{Stability Analysis}

Using (1), (3), and (7) the following error dynamics can be obtained:

$$
\dot{e}=\sum_{i=1}^{5} h_{i}\left[\begin{array}{ccc}
0 & 1 & 0 \\
-K_{P i} & -K_{D i} & 0 \\
0 & 0 & -K_{3 i}
\end{array}\right] e
$$


TABLE I

PMSM SPECIFICATIONS

\begin{tabular}{|c|c|}
\hline Parameters & Items \\
\hline Number of poles $(p)$ & 12 \\
\hline Stator resistance $\left(R_{S}\right)$ & $0.99[\Omega]$ \\
\hline Stator inductance $\left(L_{S}\right)$ & $5.82[\mathrm{mH}]$ \\
\hline Magnetic flux $\left(\lambda_{m}\right)$ & $0.079153[\mathrm{~V} . \mathrm{sec} / \mathrm{rad}]$ \\
\hline Equivalent inertia $(J)$ & $0.00120754\left[\mathrm{~kg} \cdot \mathrm{m}^{2}\right]$ \\
\hline Viscous friction coefficient $(B)$ & $0.0003[N . \mathrm{m.sec} / \mathrm{rad}]$ \\
\hline Load torque $\left(T_{L}\right)$ & $0.7[\mathrm{~N} . \mathrm{m}]$ \\
\hline
\end{tabular}

which yields the characteristic function (6) with:

$$
\begin{aligned}
& a_{2} \in\left[K_{D 0}+K_{33}, K_{D 3}+K_{30}\right], \\
& a_{1} \in\left[K_{33} K_{D 0}+K_{P 3}, K_{30} K_{D 3}+K_{P 0}\right], \\
& a_{0} \in\left[K_{33} K_{P}, K_{30} K_{P 0}\right]
\end{aligned}
$$

where, $K_{P 0}=\max \left\{K_{P 1}, K_{P 5}\right\}, K_{D 0}=\min \left\{K_{D 1}, K_{D 5}\right\}$, and $K_{30}=\max \left\{K_{31}, K_{35}\right\}$. By [11] it can be seen that the characteristic function (6) with (9) is asymptotically stable if:

$$
\left(K_{D 0}+K_{33}\right)\left(K_{33} K_{D 0}+K_{P 3}\right)>K_{P 0} K_{30}
$$

This proves the following theorem:

Main Theorem: Consider the closed-loop system of (1) and (2) with the linearizing control law (3) and the fuzzy PD control law (7). Then, the asymptotic stability of $e=0$ is guaranteed as long as the PD parameters satisfy the conditions of (10).

\section{Simulation And Experimental Results}

For the simulations and experiments, a PMSM (1) with the system parameters given in Table I was considered. Thus, the PMSM model equations can be rewritten as follows:

$$
\begin{aligned}
& \dot{\omega}=3539.6 i_{q s}-0.2484 \omega-4968.8 T_{L} \\
& \dot{i}_{q s}=-170.1 i_{q s}-13.6 \omega+171.8 V_{q s}-\omega i_{d s} \\
& \dot{i}_{d s}=-170.1 i_{d s}+171.8 V_{d s}+\omega i_{q s}
\end{aligned}
$$

Using (3), the linearizing control terms $u_{f q}$ and $u_{f d}$ are given by:

$$
\begin{aligned}
& u_{f q}=\ddot{\omega}_{d}+0.2484 \alpha+3539.6\left(170.1 i_{q s}+13.6 \omega+\omega i_{d s}\right) \\
& u_{f d}=170.1 i_{d s}-\omega i_{q s}
\end{aligned}
$$

To obtain the fuzzy PD control law (7) that stabilizes the linearized error dynamics, the membership function and PD gains which satisfy the stability condition (10) are:

$$
\begin{aligned}
& m_{i}=e^{-\mu\left(\omega_{e}-W_{i}\right)^{2}}, \\
& W_{1}=-W_{5}=-1000, W_{2}=-W_{4}=0.5 W_{1}, W_{3}=0, \\
& \mu=1=W_{1}^{2}, \\
& K_{P 1}=K_{P 5}=70000, K_{P 2}=K_{P 4}=65000, K_{P 3}=50000, \\
& K_{D 1}=K_{D 5}=100, K_{D 2}=K_{D 4}=400, K_{D 3}=600, \\
& K_{31}=K_{35}=700, K_{32}=K_{34}=600, K_{33}=500 .
\end{aligned}
$$

For a comparative study, a linearizing control scheme with the conventional non-fuzzy PD controller (4) was also carried out. In this case, the PD gains are given by:

$$
K_{P}=K_{P 1}=70000, K_{D}=K_{D 1}=100, K_{3}=K_{31}=700 .
$$

Fig. 3 shows the overall control system which consists of a PMSM, an encoder, a brake for the load torque, and a threephase PWM inverter with a TMS320F28335 DSP controller.

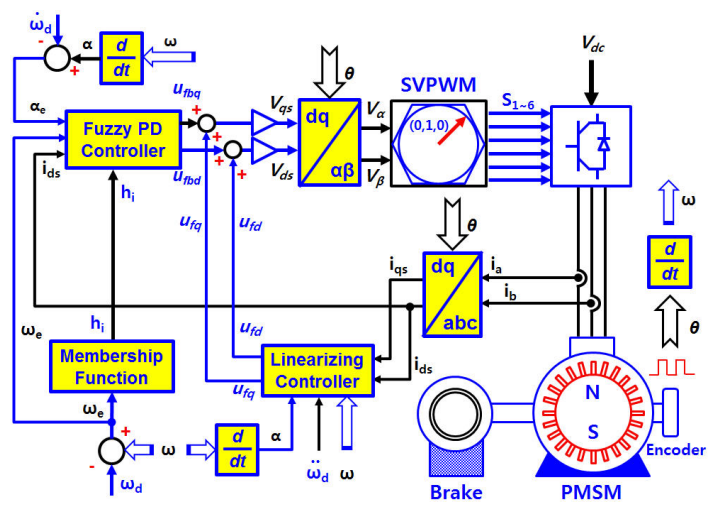

Fig. 3. Overall block diagram of the proposed control system.
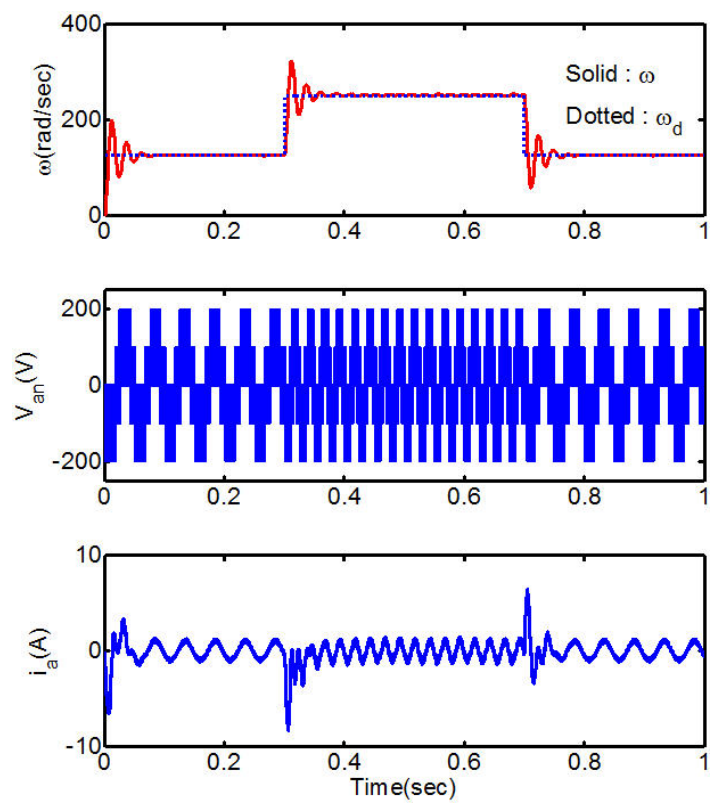

Fig. 4. Simulation results with the non-fuzzy PD controller.

In this paper, the switching frequency is chosen as $5[\mathrm{kHz}]$, and a space vector PWM (SVPWM) technique is used to realize the control input applied to the motor. To evaluate the control performance under a step speed change, the reference speed $\left(\omega_{d}\right)$ increases from $125.66[\mathrm{rad} / \mathrm{sec}]$ to $251.33[\mathrm{rad} / \mathrm{sec}]$ and then decreases from $251.33[\mathrm{rad} / \mathrm{sec}]$ to $125.66[\mathrm{rad} / \mathrm{sec}]$.

The proposed control algorithm is simulated using Matlab/Simulink for two cases: a conventional non-fuzzy PD controller (14) and the proposed fuzzy PD controller (13). Figs. 4 and 5 show the simulation results for the speed response with a conventional non-fuzzy PD controller and the proposed fuzzy PD controller, respectively. As can be seen in the figures, the proposed PD method assures a better transient performance such as no overshoot and a fast settling time when compared with the conventional PD method. Fig. 6 shows the experimental test bed, which includes a three-phase inverter with a TI DSP TMS320F28335, a surface-mounted PMSM, and a brake for the load torque. Figs. 7 and 8 show the experimental results under the same condition as Figs. 4 and 5, respectively. Figs. 7 (a) and 8 (a) show the desired speed $\left(\omega_{d}\right)$ and the measured speed $(\omega)$ under a conventional nonfuzzy PD controller and the proposed fuzzy PD controller, respectively. Figs. 7 (b) and 8 (b) show the line to neutral 

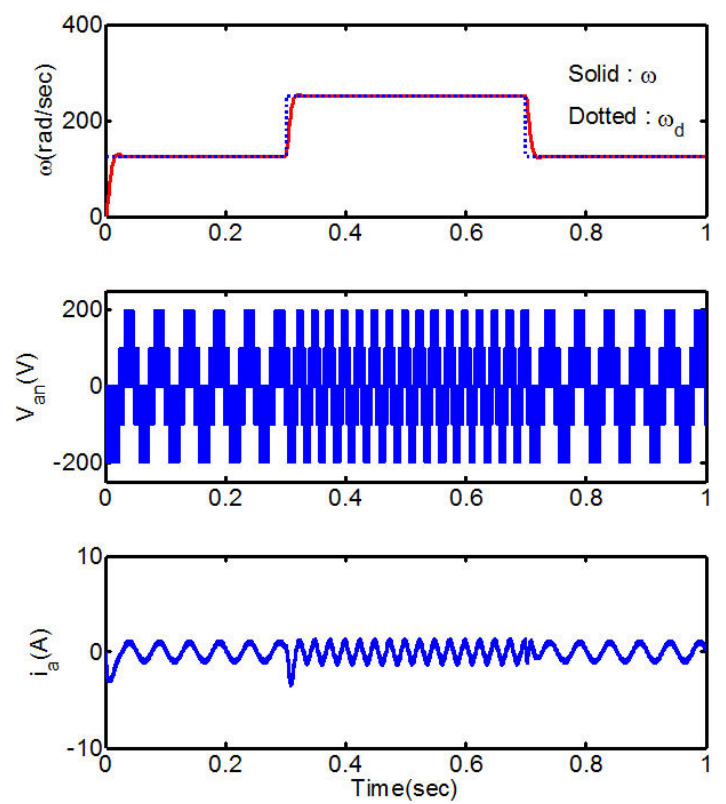

Fig. 5. Simulation results with the proposed fuzzy PD controller.

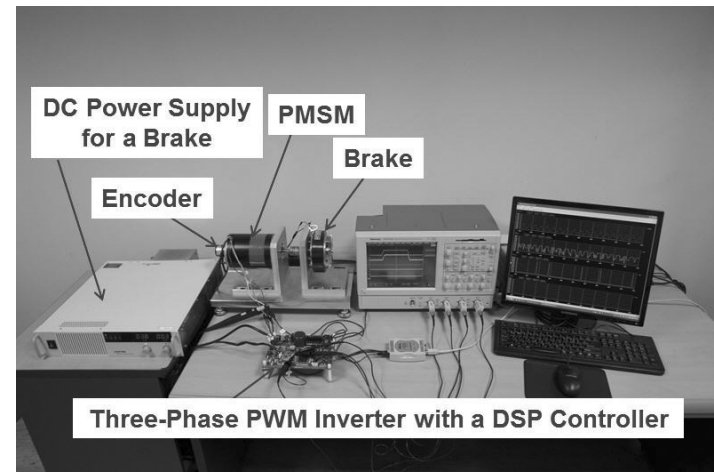

Fig. 6. Experimental test bed.

voltage $\left(V_{a n}\right)$ and the phase $a$ current $\left(i_{a}\right)$ under a conventional non-fuzzy PD controller and the proposed fuzzy PD controller, respectively. From the simulation and experimental results, it can be seen that the control performance of the proposed fuzzy PD control law is much better than that of the conventional non-fuzzy PD controller.

\section{CONCLUSIONS}

Motivated by the common control engineering knowledge that transient performance can be improved if the control input is big at the beginning, a linearizing control scheme with a fuzzy PD controller was proposed. Also, the stability condition, which guarantees the asymptotic stability of the overall system, was analytically derived. Finally, the effectiveness of the proposed method was verified by simulation and experimental results.

\section{ACKNOWLEDGMENT}

This research was supported by the Basic Science Research Program through the National Research Foundation of Korea (NRF) funded by the Ministry of Education, Science and Technology (No. 2010-0009577).

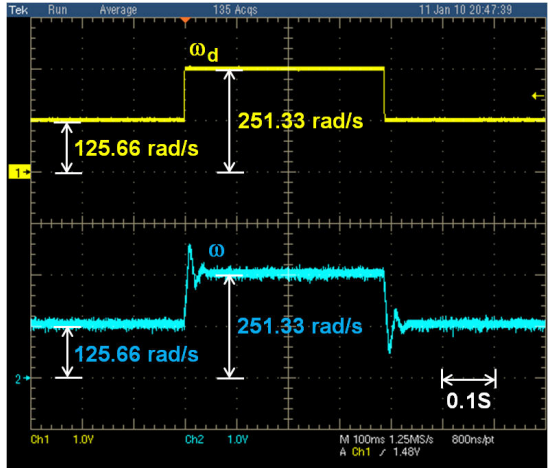

(a) Desired speed $\left(\omega_{d}\right)$ and measured speed $(\omega)$.

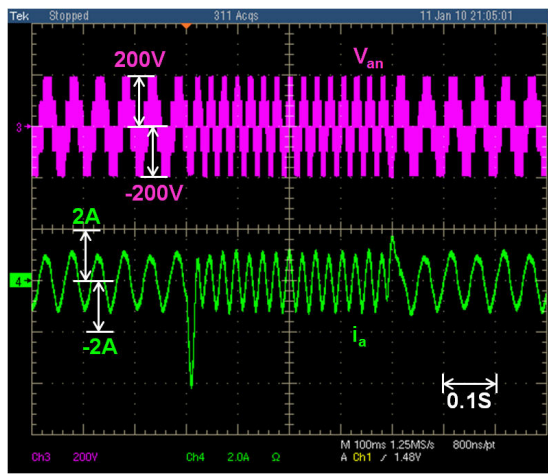

(b) Line to neutral voltage $\left(V_{a n}\right)$ and phase $a$ current $\left(i_{a}\right)$.

Fig. 7. Experimental results with the non-fuzzy PD controller.

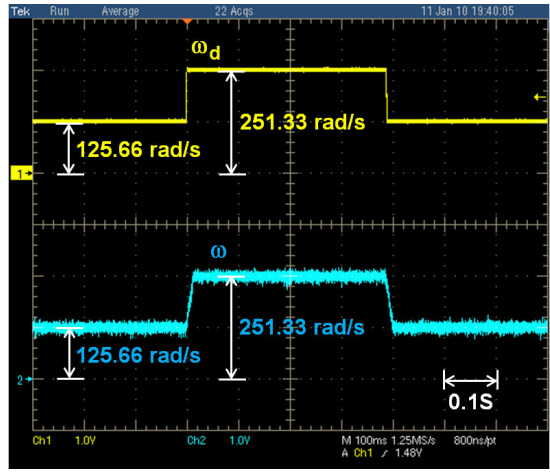

(a) Desired speed $\left(\omega_{d}\right)$ and measured speed $(\omega)$.

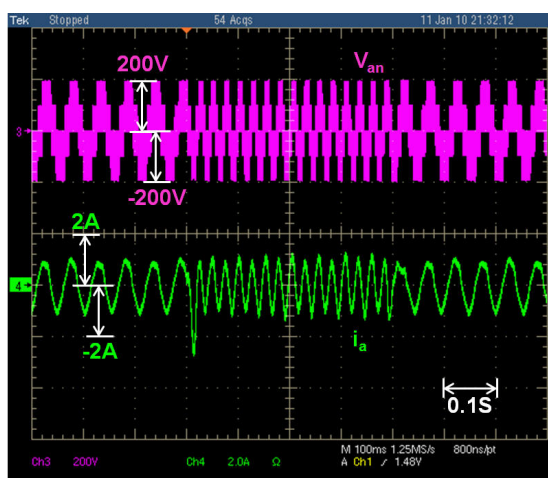

(b) Line to neutral voltage $\left(V_{a n}\right)$ and phase $a$ current $\left(i_{a}\right)$.

Fig. 8. Experimental results with the proposed fuzzy PD controller. 


\section{REFERENCES}

[1] H. S. Kang, C. K. Kim, and Y. S. Kim, "Position control for interior permanent magnet synchronous motors using an adaptive integral binary observer," Journal of Electrical Engineering \& Technology, Vol. 4, No. 2, pp. 240-248, Jun. 2009.

[2] J. G. Lee, K. H. Nam, S. H. Lee, S. H. Choi, and S. W. Kwon, "A lookup table based loss minimizing control for FCEV permanent magnet synchronous motors," Journal of Electrical Engineering \& Technology, Vol. 4, No. 2, pp. 201-210, Jun. 2009.

[3] K. Hartani, Y. Miloud, and A. Miloudi, "Improved direct torque control of permanent magnet synchronous electrical vehicle motor with proportional-integral resistance estimator," Journal of Electrical Engineering \& Technology, Vol. 5, No. 3, pp. 451-461, Sep. 2010.

[4] M. Cheng, Q. Sun, and E. Zhou, "New self-tuning fuzzy PI control of a novel doubly salient permanent-magnet motor drive," IEEE Trans. Ind. Electron., Vol. 53, No. 3, pp. 814-821, Jun. 2006.

[5] Y. S. Kung, C. C. Huang, and M. H Tsai, "FPGA realization of an adaptive fuzzy controller for PMLSM drive," IEEE Trans. Ind. Electron., Vol. 56, No. 8, pp. 2923-2932, Aug. 2009.

[6] S. Li and Z. Liu, "Adaptive speed control for permanent-magnet synchronous motor system with variations of load inertia," IEEE Trans. Ind. Electron., Vol. 56, No. 8, pp. 3050-3059, Aug. 2009.

[7] Y. S. Kung and M. H. Tsai, "FPGA-based speed control IC for PMSM drive with adaptive fuzzy control," IEEE Trans. Power Electron., Vol. 22, No. 6, pp. 2476-2486, Nov. 2007.

[8] M. N. Uddin and M. A. Rahman, "High-speed control of IPMSM drives using improved fuzzy logic algorithms," IEEE Trans. Ind. Electron., Vol. 54, No. 1, pp. 190-199, 2007.

[9] P. Korba, R. Babuska, H. B. Verbruggen, and P. M. Frank, "Fuzzy gain scheduling: Controller and observer design based on Lyapunov method and convex optimization," IEEE Trans. Fuzzy Syst., Vol. 11, No. 3, pp. 285-298, Jun. 2003.

[10] Z. Y. Zhao, M. Tomizuka, and S. Isaka, "Fuzzy gain scheduling of PID controllers," IEEE Trans. Syst., Man, and Cybern., Vol. 23, No. 5, pp. 1392-1398, Sep./Oct. 1993.

[11] M. B. Argoun, "On the stability of low-order perturbed polynomials," IEEE Trans. Autom. Control., Vol. 35, No. 2, pp. 180-182, Feb. 1990.

[12] J. J. E. Slotine and W. Li, Applied Nonlinear Control, Prentice Hall, Englewood Cliffs, NJ, 1991.

[13] K. H. Kim and M. J. Youn, "A nonlinear speed control for a PM synchronous motor using a simple disturbance estimation technique," IEEE Trans. Ind. Electron., Vol. 49, No. 3, pp. 524-535, Jun. 2002.

[14] F. F. M. El-Sousy, "Robust adaptive wavelet-neural-network slidingmode speed control for a DSP-based PMSM drive system", Journal of Power Electronics, Vol. 10, No. 5, pp. 505-517, Sep. 2010.

[15] Y. Zhang, C. M. Akujuobi, W. H. Ali, C. L. Tolliver, and L. S Shieh, "Load disturbance resistance speed controller design for PMSM," IEEE Trans. Ind. Electron., Vol. 53, No. 4, pp. 1198-1208, Aug. 2006.

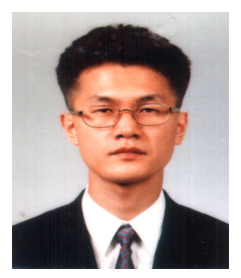

Jin-Woo Jung received his B.S. and M.S. in Electrical Engineering from Hanyang University, Seoul, Korea, in 1991 and 1997, respectively, and his Ph.D. in Electrical and Computer Engineering from The Ohio State University, Columbus, Ohio, USA, in 2005. From 1997 to 2000, he was with the Digital Appliance Research Laboratory, LG Electronics Co., Ltd., Seoul, Korea. From 2005 to 2008 , he worked at the R\&D Center and with the PDP Development Team, Samsung SDI Co., Ltd., Korea, as a Senior Engineer. Since 2008, he has been an Assistant Professor with the Division of Electronics and Electrical Engineering, Dongguk University, Seoul, Korea. His current research interests include electric machine drives, the control of distributed generation systems using renewable energy sources (wind turbines, fuel cells, solar cells, etc.), the design and control of power converters, and the driving circuits and driving methods of ac plasma display panels (PDP).

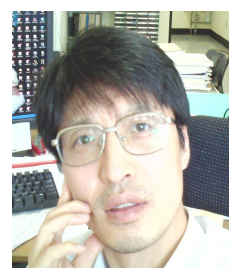

Han Ho Choi received his B.S. in Control and Instrumentation Engineering from Seoul National University, Seoul, Korea, in 1988, and his M.S. and Ph.D in Electrical Engineering from the Korea Advanced Institute of Science and Technology (KAIST), Daejeon, Korea, in 1990 and 1994, respectively. From 1994 to 1998 , he was a Team Leader with the Advanced Technology Laboratory, DaeWoo Electrical Company. $\mathrm{He}$ is currently with the Division of Electronics and

Electrical Engineering, Dongguk University, Seoul, Korea. He spent his sabbatical with the Department of Electrical and Computer Engineering, California State Polytechnic University, Pomona, USA. He teaches introductory electrical engineering courses on microprocessors, robotics, sensors, and instrumentation engineering. His current research interests include linearmatrix-inequality-based control system design, microprocessor-based control systems, and variable structure systems.

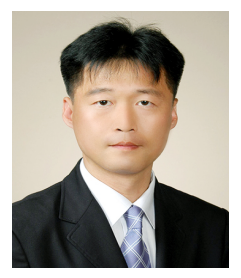

Tae-Heoung Kim received his B.S., M.S., and Ph.D. in Electrical Engineering from Hanyang University, Seoul, Korea, in 1993, 1995, and 2005, respectively. From 1995 to 2002, he worked for LG Electronics as a Senior Research Engineer. Since 2005, he has been a Professor in the Department of Electrical Engineering, Gyeongsang National University. His research interests include the design of electric machines and control systems. 